\title{
Design of Respiration Rate Meter Using Flexible Sensor
}

\author{
Sarah Aghnia Miyagi ${ }^{\sharp, 1}$, Muhammad Ridha Mak’ruf ${ }^{1}$, Endang Dian Setyoningsih ${ }^{1}$, Tarak Das ${ }^{2}$ \\ ${ }^{1}$ Department of Electromedical Engineering Poltekkes Kemenkes, Surabaya \\ Jl. Pucang Jajar Timur No. 10, Surabaya, 60245, Indonesia \\ ${ }^{2}$ Department of Biomedical Engineering Netaji Subhash, Engineering College Kolkata, India \\ \#aghniamiyagi@gmail.com, m.reedha@gmail.com, diancholik@gmail.com, tarakjubme@gmail.com
}

\begin{abstract}
Respiration rate is an important physiological parameter that helps to provide important information about the patient's health status, especially from the human respiratory system. So it is necessary to measure the human respiratory rate by calculating the number of respiratory frequencies within 1 minute. The respiratory rate meter is a tool used to calculate the respiratory rate by counting the number of breaths for 1 minute. The author makes a tool to detect human respiratory rate by using a sensor that detects the ascend and descend of the chest cavity based on a microcontroller so that the operator can measure the breathing rate more practically and accurately. Component tool contains analog signal conditioning circuit and microcontroller circuit accompanied by display in the form of LCD TFT. The results of measurement data on 10 respondents obtained an average error value, namely the position of the right chest cavity $6.6 \%$, middle chest cavity $7.92 \%$, and left chest cavity $6.85 \%$. This value is still below the error tolerance limit of $10 \%$. It can be concluded that to obtain the best measurement results, the sensor is placed in the position of the right chest cavity.
\end{abstract}

Keywords—Flex Sensor; Respiration Rate; Breath Per Minutes

\section{INTRODUCTION}

The respiratory rate meter is a tool used to calculate the respiratory rate by counting the number of breaths for 1 minute [1]. This measurement can be done to determine the health of the patient's condition associated with breathing. The amount of breathing that exceeds the normal respiratory rate (tachypnea), is lower than the average number of normal respiration (bradypnea), or even stops for a while (apnea), is a sensitive indicator for physiological sufferers who need immediate health care [2].

There are four important physiological parameters that can be used by nurses or medical personnel in determining the health status of patients in hospitals. The four parameters are body temperature, heart rate, respiratory rate, and blood pressure. Of the four parameters, the respiratory rate is the most important parameter because the respiratory rate can provide valuable information related to the condition of the heart, nerves, and lungs [2]. Respiratory rate is a vital sign used to monitor the progress of the disease and abnormal respiratory rate. There is substantial evidence that changes in respiratory rate can be used to predict potentially serious clinical events such as a heart attack or entering the intensive care unit. These studies have shown breathing rates to be better than other vital measurements such as pulse and blood pressure in distinguishing between stable patients and patients at risk [3]. Abnormal respiratory rate and changes in respiratory rate are one indicator of instability in a person's physical condition, and in many cases, breathing rate is one of the earliest indicators of this instability. It is therefore very important to monito $\mathrm{r}$ respiratory rate as an indicator of patient status [4]. Tarak Das develop a respiration rate using thermistor [5].

The simplest method for determining the respiratory rate is to manually calculate the up and down motion of the chest wall directly, or by breathing sounds through a stethoscope. This method is very dependent on mind concentration and sensory sensitivity of the measurement / observation actors [2]. However, using a stethoscope for a long time is not practical and inaccurate mainly due to human error [6]. Because of human nature that is easy to forget, tired, and bored, it is now widely developed the method of measuring or observing breathing rates electronically [2]. A study comparing respiration measurement using a calculator and manual measurement showed the benefits of using digital counting techniques [7].

In 2014 I Made Naradhyana made a Monitoring Device of Respiratory System Using Arduino UNO and E-Health PCB" using an air flow sensor and the results were displayed on the Nokia 5110 LCD. Subsequently in 2015 Wendi Era Sonata and Wildan made a tool Designing a Measuring Instrument Human Respiratory Rate Based on AT mega 8535 Microcontroller uses the LM35 sensor and is displayed on the LCD character $2 \times 16$. In 2017 Desy Yuniar Ekawati made a device with title of Designing Respiratory Rate Measurement Using Mic Condenser Accompanied by Plotting on LCD Graphics and in 2018 Erdiana Larasati has perfected the module by displaying the output on a TFT LCD and using a humidity sensor. From the results of identification of some of these studies, even though using a different sensor but have the same thing in laying the sensor, namely in the mouthpiece or mouth mask. While data collection 
for the respiratory rate is not only covered but can also be on the ribs or stomach [8].

Based on the problem above, on this occasion the author wants to perfect the design of the respiratory rate measurement device by retrieving data on the up and down motion of the chest cavity because the previous device used a sensor that placed it in the mouthpiece or mouth mask. The author uses a flex sensor with TFT LCD output that is equipped with normal (eupnea) and abnormal information with 2 criteria: bradypnea and tachypnea.

\section{MATERIALS AND METHODS}

\section{A. Experimental Setup}

This study used ten subjects with the criteria the ages ranged between 20 and 35 years old. The subjects were randomly sampled and the data collection is repeated for 3 times at 3 placement points.

\section{1) Materials and Tool}

This study is used a flex sensor to detects the ascend and descend of the chest cavity. The sensor were attached by the strap around the chest. PSA was built based on LM358 OPAMP. The Arduino Nano microcontroller was used to convert analogue output from flex sensor to digital output. TFT LCD was used to display the final output.

\section{2) Experiment}

In this study, after the design was completed then the Respiration Rate Meter was tested using a counter. By showing the criteria (eupnea, bradypnea, tachypnea), the Respiration Rate Meter was tested with ranged between 1 and 100 . Then the Respiration Rate Meter was tested on the human body.

\section{B. The Diagram Block}

In this research, the flex sensor detects the ascend and descend of the chest cavity in 1 minute. Then, the input from sensor will enter to PSA. In Arduino microcontroller was used to convert analog data from PSA into digital. The Respiratory Rate data will be displayed on the TFT LCD in the form of a number of respiratory rates along with information on bradypnea, eupnea, and tachypnea.

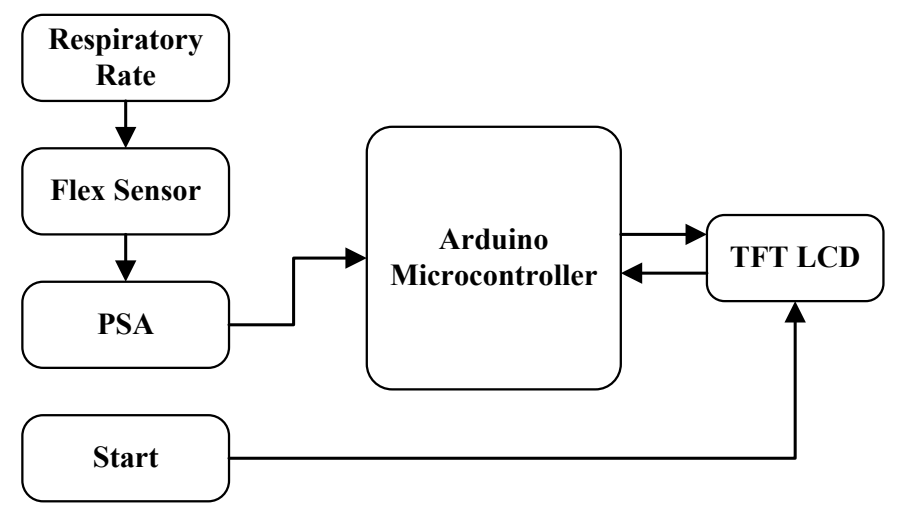

Fig. 1. The diagram block of the Respiration Rate Meter

\section{The Flowchart}

The Arduino program was built based on the flowchart as shown in Fig. 2. After the initialization of the Arduino, the program starts to count the Respiration Rate for 1 minute. If it's already 1 minute, then the value of Respiration Rate will be shown to TFT LCD with the criteria (bradypnea, eupnea, tachypnea).

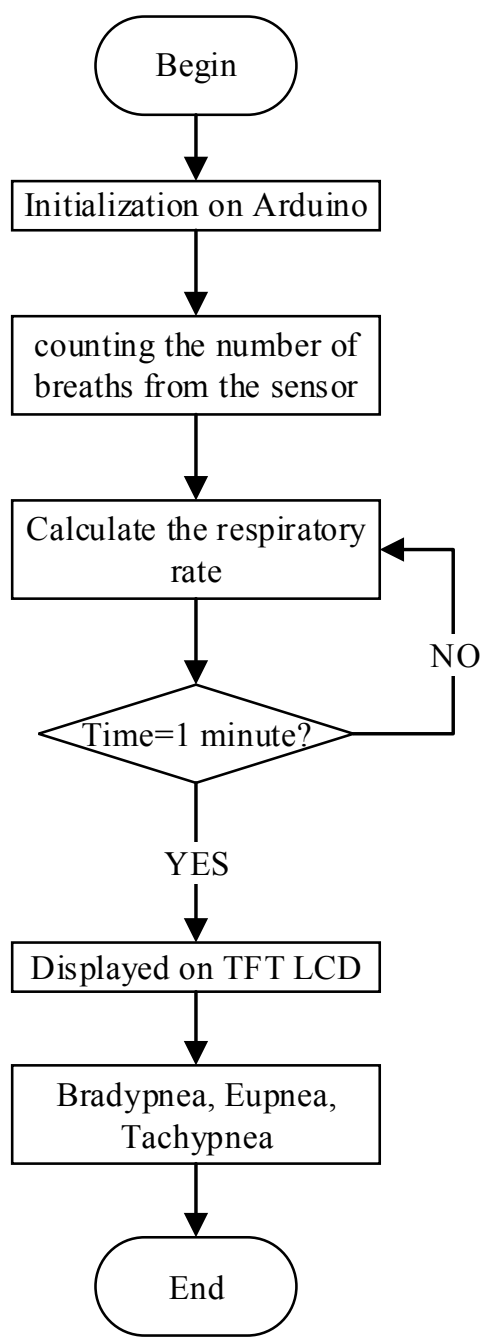

Fig. 2. The Flowchart of the Arduino Program

\section{The Analog Circuit}

The important part of this development is the analogue circuit which describes in Fig. 3 (voltage divider), Fig. 4 (difference amplifier). The circuit is used to process the Respiration Rate. Hence it will ready for digital processing using Arduino.

\section{1) Voltage Divider}

Flex sensor is a sensor that when it's curved, the resistance which is output from the sensor will be changed. So that when the flex sensor is curved it will make output from the voltage 
divider change depending on the resistance produced when it's being curved. This circuit is composed of two resistor. The value of $\mathrm{R} 1$ is $47 \mathrm{~K}$ ohms and the other one is flex sensor. For the calculation of output from voltage divider, as follows:

$$
\text { Vout }=\frac{R g}{\text { Rflex }+ \text { Rground }} . \text { Vin }
$$

Where, $\mathrm{Rg}$ is resistor to ground then Rflex is resistance which output from flex sensor. Vout is voltage output from this circuit and Vin is voltage input for this circuit.

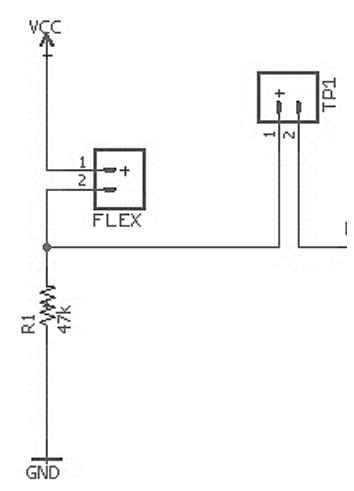

Fig. 3. Voltage Divider

\section{2) Difference Amplifier}

The Difference Amplifier is to get the difference value of Vin non-inverting with Vin inverting and also its functions to gained the difference in value from the input voltage. Multiturn is to set if the sensor if in a curved condition the output of the circuit is $0 \mathrm{~V}$. When the flex sensor is curved, the output of this circuit is no longer $0 \mathrm{~V}$, the output value of this circuit varies depending on the curvature that occurs in the flex sensor itself. The output of the difference amplifier circuit is connected to the pin A1 of Arduino Nano.

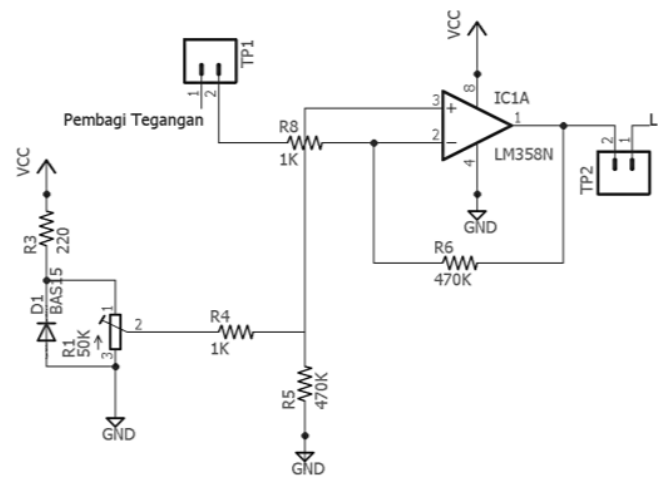

Fig. 4. Difference Amplifier

The difference amplifier was designed for eliminate the voltage and to gain the output. The gain were calculated based on Eq. 2, respectively. In this study, the gain was $470 \mathrm{x}$.

$$
\mathrm{Acl}=\frac{R f}{R i n}
$$

Where, Acl is gain for this circuit output. Rf is resistor feedback which R6 in Fig. 4. and Rin is resistor input which R8 in Fig. 4.

\section{RESULTS}

In this study, comparison of data results with predetermined comparison tools, measurement and analysis of the error value. The result shows that the Respiration Rate Meter is feasible to see the value of respiration rate from the human body.

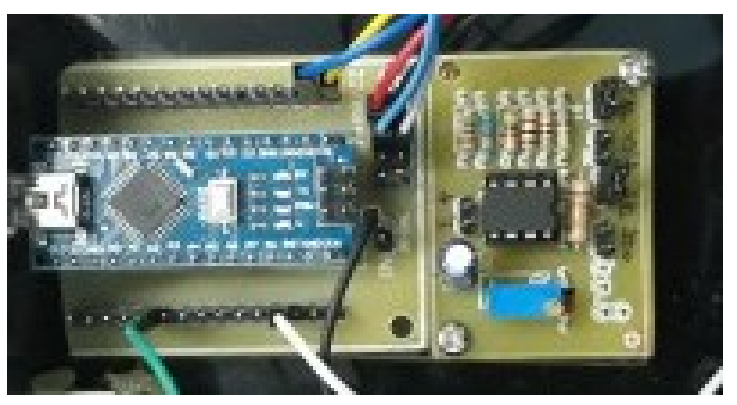

Fig. 5. The analogue part and digital part of Respiration Rate Meter

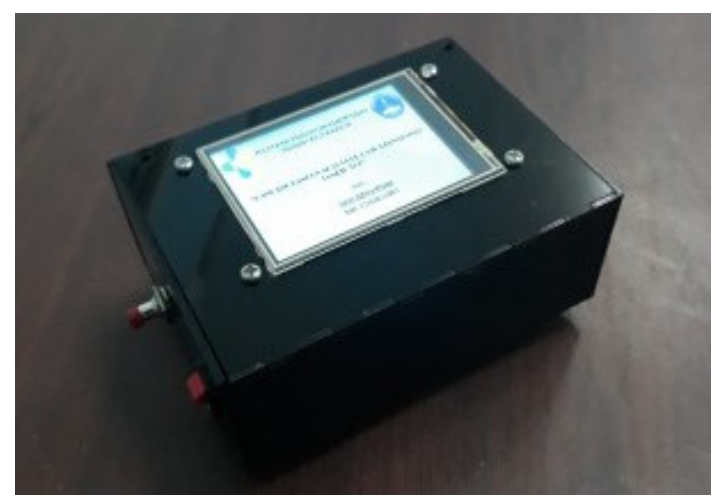

Fig. 6. The Design of Respiration Rate Meter

1) The Respiration Rate Design

The photograph of the analogue part, digital part, and design of the Respiration Rate was shown in Fig. 5 and Fig. 6, respectively. The analogue part consisted of LM358 (OP-AMP). There was also some variable resistor (multiturn 50k) for offset adjustment. The digital part consisted of the Arduino Nano microcontroller which is the main board of Respiration Rate device.

2) Respiration Rate Calculation Using Auto Reference Result

Listing program 1. Program to calculate the respiration rate

flex $=$ analogRead $(\mathrm{A} 1)$

if $($ ref $<=$ flex $)\{$ ref $=$ flex; $\}$ 


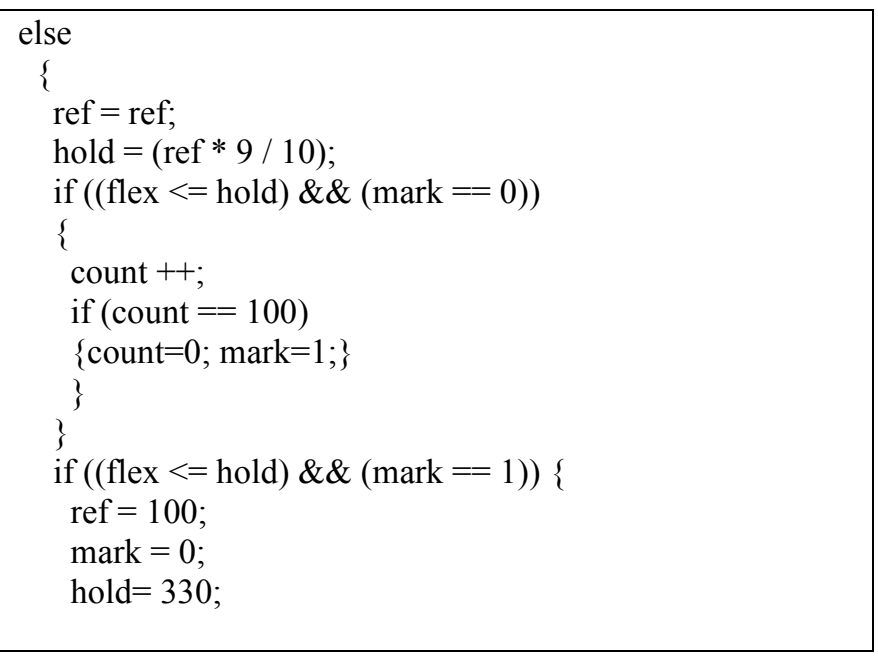

The data processing program listing on Arduino starts from reading the $\mathrm{ADC}$ through pin $\mathrm{A} 1$ and converting $\mathrm{ADC}$ data to voltage. In the above program listings use an auto reference system that uses the highest percentage of signal voltage to calculate respiration rate.

3) The value of respiration within 1 minute

Listing Program 2. Program to counting the Respiratory Rate after 1 minute

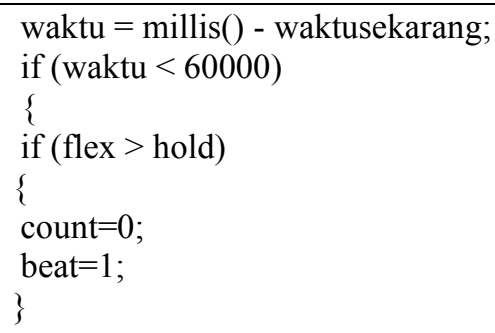

The program is to display the patient's respiration value within 1 minute. The value is displayed within 1 minute because it is a stable time when the tool is attached to the patient.

\section{4) The Listing Program for TFT LCD}

In the TFT programming, the program was grouped into some part namely: a program to send communication to displayed into TFT LCD (Listing Program 3), a program to show the value of respiration rate (breath per minute) as shown in the Listing Program 4, and a program to show the classification of respiration rate to TFT (bradypnea, eupnea, tachypnea) as shown in the Listing Program 5.

Listing Program 3. Program to send communication into TFT

void $\operatorname{setup}()\{$

Serial.begin(9600); delay(500);

Serial.print("baud=115200");

Serial.write(0xff);

Serial.write(0xff);

Serial.write(0xff);

Serial.end();

Serial.begin(115200);

The Listing Program 3. was used to send communication serial into TFT LCD. The setting of baud rate is 115200 which is fixed value for this.

Listing Program 4. Program to show the value of respiration rate

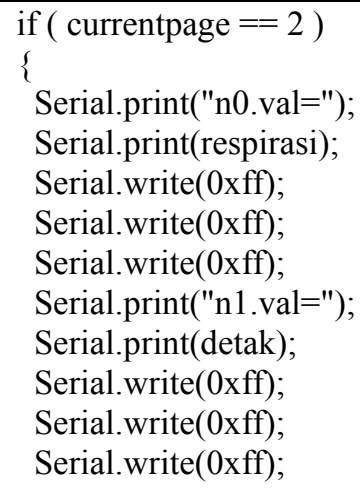

The Listing Program 4. was used to show the value of respiration rate. After the program in Arduino count the respiration rate within 1 minute, then it will show up to TFT.

Listing Program 5. Program to show the classification of respiration rate

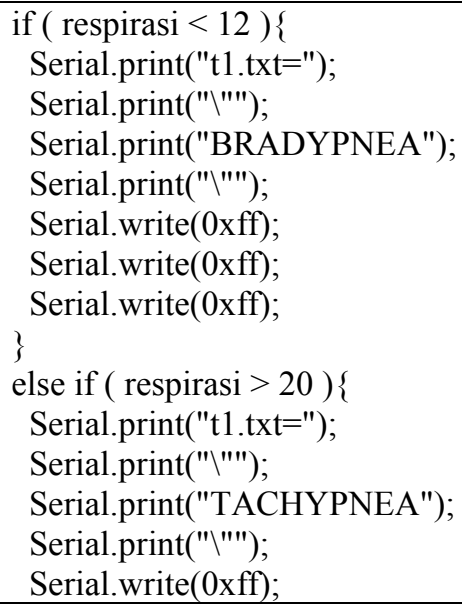




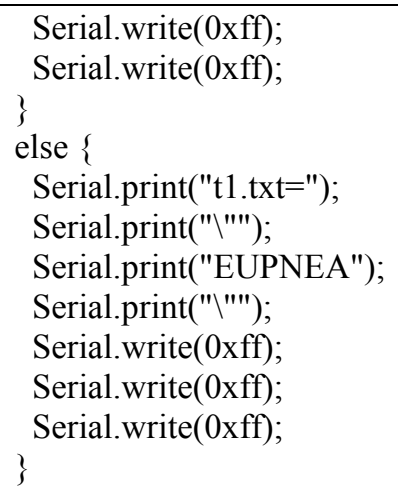

The listing program 5. was used to show the classification of respiration rate. After the value of respiration rate shown into TFT, the classification will be appear after all. There are 3 classification of respiration rate, first is bradypnea, second is eupnea or normal and the last is tachypnea.

5) The Error of Respiration Rate (Breath Per Minutes) value The validation of the Respiration Rate value shown in the TFT LCD was compared with counter. The following are data from 3 different measurement points (right chest, middle chest, left chest) for the same patient, different placements are intended as an analysis of several respiratory points in humans. The error are showed in the table I, II, and III.

TABLE I. MEASURENMENT ERROR POINT I (RIGHT CHEST)

\begin{tabular}{ccc}
\hline No & Subject & Error (\%) \\
\hline $\mathbf{1}$ & P1 & $13,64 \%$ \\
\hline $\mathbf{2}$ & P2 & $4,08 \%$ \\
\hline $\mathbf{3}$ & P3 & $10,87 \%$ \\
\hline $\mathbf{4}$ & P4 & $6,9 \%$ \\
\hline $\mathbf{5}$ & P5 & $3,08 \%$ \\
\hline $\mathbf{6}$ & P6 & $13,21 \%$ \\
\hline $\mathbf{7}$ & P7 & $1,47 \%$ \\
\hline $\mathbf{8}$ & P8 & $0 \%$ \\
\hline $\mathbf{9}$ & P9 & $2,22 \%$ \\
\hline $\mathbf{1 0}$ & P10 & $10,53 \%$ \\
\hline
\end{tabular}

Comparison of data retrieval is done by comparing the module with a comparison device (counter) carried out on 10 different subjects for respiration rate which sensor placement on the right chest, the highest error calculated is $13,64 \%$.

TABLE II. MEASURENMENT ERROR POINT II (MIDDLE CHEST)

\begin{tabular}{ccc}
\hline No & Subject & Error (\%) \\
\hline $\mathbf{1}$ & P1 & $11,11 \%$ \\
\hline
\end{tabular}

\begin{tabular}{ccc}
\hline $\mathbf{2}$ & P2 & $20,93 \%$ \\
\hline $\mathbf{3}$ & P3 & $8,11 \%$ \\
\hline $\mathbf{4}$ & P4 & $8,62 \%$ \\
\hline $\mathbf{5}$ & P5 & $0 \%$ \\
\hline $\mathbf{6}$ & P6 & $5,77 \%$ \\
\hline $\mathbf{7}$ & P7 & $10,96 \%$ \\
\hline $\mathbf{8}$ & P8 & $2,13 \%$ \\
\hline $\mathbf{9}$ & P9 & $8,33 \%$ \\
\hline $\mathbf{1 0}$ & P10 & $3,23 \%$ \\
\hline
\end{tabular}

Comparison of data retrieval is done by comparing the module with a comparison device (counter) carried out on 10 different subjects for respiration rate which sensor placement on the middle chest, the highest error calculated is $20,93 \%$.

TABLE III. MEASURENMENT ERROR POINT III (LEFT CHEST)

\begin{tabular}{ccc}
\hline No & Subject & Error (\%) \\
\hline $\mathbf{1}$ & P1 & $4,44 \%$ \\
\hline $\mathbf{2}$ & P2 & $15,91 \%$ \\
\hline $\mathbf{3}$ & P3 & $2,04 \%$ \\
\hline $\mathbf{4}$ & P4 & $8,51 \%$ \\
\hline $\mathbf{5}$ & P5 & $0 \%$ \\
\hline $\mathbf{6}$ & P6 & $10,91 \%$ \\
\hline $\mathbf{7}$ & P7 & $2,56 \%$ \\
\hline $\mathbf{8}$ & P8 & $6,52 \%$ \\
\hline $\mathbf{9}$ & P9 & $8,89 \%$ \\
\hline $\mathbf{1 0}$ & P10 & $8,7 \%$ \\
\hline
\end{tabular}

Comparison of data retrieval is done by comparing the module with a comparison device (counter) carried out on 10 different subjects for respiration rate which sensor placement on the left chest, the highest error calculated is $15,91 \%$.

\section{DISCUSSION}

After comparing the results between the module and the measuring instrument, the average error value of the module for placement of the sensor position in the right chest cavity is $6.6 \%$, in the left chest $6.85 \%$ and in the middle chest cavity $7.92 \%$. The average error value for all positions has a value that is still below the maximum Respiration Rate reading threshold of $10 \%$ as stated in the regulation of Minister of Health Regulation no. 363 of 1998 concerning the maximum errors allowed in this parameter.

Based on the output of the circuit in the module, namely table 1 , table 2 , and table 3 , the highest signal results when the sensor is placed in the right chest cavity. This is in accordance with the results of the smallest error value, namely the placement of 
sensors when in the right chest cavity because the higher the output signal produced, the easier it is to detect respiration, which is in the movement of up and down the chest cavity.

And for the most appropriate placement for this module is in the right chest cavity because the error value in the placement of the sensor part is fairly small compared to the placement of sensors in the left or middle chest cavity..

\section{CONClusion}

This study has shown measurements of respiratory cavity at 3 points. This study was built based on the Arduino microcontroller, analog circuit and TFT LCD as a display. This study has proven that the accuracy of measurement points determines different measuring results. In the future, this research can be made and used in small clinics in villages at low cost.

\section{REFERENCES}

[1] M. F. Maharrahman, "Monitoring Laju Pernapasan Berbasis PC ( Personal Computer ) dilengkapi dengan Volume Pernapasan," pp. 1-8, 2016.

[2] J. Fisika and F. Universitas, "BERBASIS MIKROKONTROLER ATmega8535 Wendi Era Sonata , Wildian,” vol. 4, no. 4, pp. 332-338, 2015.

[3] A. Singh and A. Chaudhary, "Real Time Respiration Rate Measurement Using Temperature Sensor,” pp. 605-607, 2017.

[4] I. M. Naradhyana, U. Sunarya, S. T. Mt, S. Hadiyoso, and S. T. Mt, "ALAT PEMANTAU SISTEM PERNAFASAN MENGGUNAKAN MIKROKONTROLLER DAN E-HEALTH PCB Monitoring Device of Respiratory System Using Arduino UNO and E-Health PCB," vol. 1, no. 1, pp. 710-719, 2015.

[5] T. Das, S. Guha, N. Banerjee, and P. Basak, "Development of thermistor based low cost high sensitive respiration rate measurement system using audio software with audio input," in 2017 Third International Conference on Biosignals, Images and Instrumentation (ICBSII), 2017, no. March, pp. 1-3.

[6] A. S. Terry, “( 12 ) United States Patent ( 45 ) Date of Patent : ( US );," vol. 2, no. 12, 2013.

[7] A. Anand, A. R. K, K. Greeshma, K. Jaseena, and R. Rahul, "Design of Digital Respiration Rate Meter,” vol. 118, no. 14, pp. 28-30, 2015.

[8] P. E. S. Cohen and A. E. D. Sykes, "United States Patent (19)," no. 19. 